Research Article

\title{
Evaluating the Tourist Climate Comfortable Period of China in a Changing Climate
}

\author{
Dan-Dan Yu $\mathbb{D}^{1,2}$ Shan $L i \mathbb{D}^{1,2,3}$ and Zhong-Yang Guo ${ }^{1,2}$ \\ ${ }^{1}$ School of Geographic Sciences, East China Normal University, Shanghai 200241, China \\ ${ }^{2}$ Key Laboratory of Geographic Information Science, Ministry of Education, Shanghai 200241, China \\ ${ }^{3}$ Institute of Eco-Chongming, Shanghai 200241, China \\ Correspondence should be addressed to Shan Li; sli@geo.ecnu.edu.cn
}

Received 20 March 2020; Accepted 30 June 2020; Published 25 July 2020

Academic Editor: Nir Y. Krakauer

Copyright $\odot 2020$ Dan-Dan Yu et al. This is an open access article distributed under the Creative Commons Attribution License, which permits unrestricted use, distribution, and reproduction in any medium, provided the original work is properly cited.

\begin{abstract}
The evaluation of climate comfort for tourism can provide information for tourists selecting destinations and tourism operators. Understanding how climate conditions for tourism evolve is increasingly important for strategic tourism planning, particularly in rapidly developing tourism markets like China in a changing climate. Multidimensional climate indices are needed to evaluate climate for tourism, and previous studies in China have used the much criticized "climate index" with low resolution climate data. This study uses the Holiday Climate Index (HCI) and daily data from 775 weather stations to examine interregional differences in the tourist climate comfortable period (TCCP) across China and summarizes the spatiotemporal evolution of TCCP from 1981 to 2010 in a changing climate. Overall, most areas in China have an "excellent" climate for tourism, such that tourists may visit anytime with many choices available. The TCCP in most regions shows an increasing trend, and China benefits more from positive effects of climate change in climatic conditions for tourism, especially in spring and autumn. These results can provide some scientific evidence for understanding human settlement environmental constructions and further contribute in improving local or regional resilience responding to global climate change.
\end{abstract}

\section{Introduction}

As tourism becomes one of the largest and fastest growing global industries, it has been playing an extremely important role in promoting national and leisure economic development around the world [1]. As shown in the International Tourism Highlights Report (UNWTO, 2019), Travel and Tourism is a key sector in promoting economic development and job creation throughout the world. International tourist arrivals grew 5\% in 2018 to reach the 1.4 billion mark. And, export earnings generated by tourism have grown to USD 1.7 trillion. The value of tourism accounted for $29 \%$ of the world's global services exports and 7\% of overall exports of goods and services in 2018. From China tourism statistics in 2019, the direct contribution of travel and tourism to China's economy and society employment reached $11.04 \%$ and $10.31 \%$, respectively. Along with its steady economic development, China also steps into a period of fast development in tourism. Being a resource-dependent industry, the tourism industry is sensitive to climate to an extent $[2,3]$. Climate change fundamentally influences the pattern of global tourism development, and thus climate change-related tourism issues have attracted more and more attention [4-6].

Comfortable and safe climatic conditions are a necessary prerequisite for the tourism development. Climate comfortableness is a bioclimatic indicator evaluating people's physical comfort/discomfort within different meteorological environments. Studies on climate comfortableness are of substantial significance to architectural design $[7,8]$, public health $[9,10]$, travel behavior $[11,12]$ etc., especially to the development of destinations for vacations. An important approach in researching this area is climate comfort assessment. For tourism, climate as a resource is multifaceted and involves a complexity of weather variables [13], and therefore choosing a suitable index for assessing climate is 
critical. Over the past century, more than 100 indexes have been proposed and developed to assess climate comfortableness [14-16], which can be further classified into two types: "empirical index" or "rational index" [15, 17-19]. Accordingly, scholars evaluate the tourism climate comfortableness of tourism in different regions of China in terms of relevant indexes of climate comfortableness [20-22]. However, the "empirical index" and "rational index" only consider the thermal of human's body, which is insufficient for studying tourism activities. In discussing the tourism seasonality, thermal, physical, and aesthetic components should all be taken into account, as suggested by de Freitas et al. [13, 14]. Many tourism climate indexes have been proposed and developed, such as Tourism Climate Index (TCI) [23], Beach Climate Index (BCI) [24], Climate Index for Tourism (CIT) [13], Modified Climate Index for Tourism (MCIT) [25], and Holiday Climate Index (HCI) [26]. HCI consists in the conceptual design recommended by de Freitas et al. $[13,14]$ and applies a higher temporal scale of the climate (i.e., daily average). Further, HCI has been widely applied to assess the tourism climate suitability, in Iran [27, 28], Indonesia [29], Caribbean destinations [30], and Europe [26].

Research has been limited on evaluating daily climate adaptation using the HCI for tourism purposes in China and the world. The tourist climate comfortable period (TCCP), as the carrier of the tourist climate comfortableness degree duration, is of great significance to the architectural design, the robustness of tourists, and the development of the tourism industry. The purpose of this study, therefore, is to investigate the potential of climate condition in China for tourist attraction and to evaluate the suitability of TCCP in a changing climate. This study further explains its research methods, implementation, and key results. Finally, findings and implications are discussed for future research in assessing current and future climatic suitability for tourism.

\section{Literature Review}

Facing with multifaceted challenges from climate variability and climate change, tourism researchers need to make sense of the changing climate trends for mitigation strategies for tourism. Following this logic, climate comfortableness plays a fundamental role for social wellbeing and tourism development. In this sense, there is an increasing demand for customized climate-related tools and techniques that enables the effective transition of climate information into decisionrelevant information [12]. Indices are a tool for evaluating climate resources that may be used to simplify the complexity of the human-environment multifaceted climate information. Comfort Index of Human Body, either "empirical index" or "rational index" [15, 17-19], has dominated in the literature over the past century. "Empirical index" refers to indexes on subjective feelings or physiological reaction considerations, which contains Effective Temperature (ET) [31], Temperature Humidity Index (THI) [32], Wind Effect Index (WEI) [33], etc. "Rational Index/Model" is represented by Predicted Mean Vote-Predicted Percent Dissatisfied (PMV-PPD) [34], Physiological Equivalent
Temperature (PET) [35], Universal Thermal Climate Index (UTCI) $[18,36]$, etc. Yu et al. [20] used the THI, Wind Chill Effect (WCI), and Index of Clothing (ICL) to evaluate summer climate comfort degree and tourism attractiveness potential in northern China. For instance, Chi et al. [21] employed PET and UTCI to evaluate thermal comfort and its dynamics of 31 provincial capital cities of China over the past 30 years. Yang [22] analyzed the spatial differentiation of China's summer tourist destinations using the UTCI and analytic hierarchy process model from 1960 to 2014 .

However, even if the temperature is acceptable, unpleasant weather conditions may prevent outdoor activities $[37,38]$. Furthermore, certain outdoor tourism themes such as ski tourism or beach tourism, in particular, are highly weather-sensitive with unique climate requirements $[12,39,40]$. These requirements call for indexes of evaluating climate for tourism. Over the past 30 years, many tourism climates indexes have been proposed and developed. It is Mieczkowski [23] that firstly devised a TCI (Tourism Climate Index) as a composite measure of tourist activities. Mainly due to its integration of three climatic facets (thermal, physical, and aesthetic) and the characters of widespread suitability and applicability, it has been used to assess a destination's current conditions and potential [41-43] and examine future climatic conditions [44-47]. However, TCI has many deficiencies such as coarse temporal resolution (1 month), lacking the overriding effect of physical variables (wind and rain), neglecting the subjectivity of the thresholds, and weather-sensitive activities $[26,48]$. Based on regional outdoor surveys, Morgan et al. [24] developed a user-based Beach Climate Index (BCI), which contains the same elements as TCI except for the daily thermal component, to assess the climate suitability of coastal destinations specific for beach recreation. De Freitas et al. [13] integrated the various facets of climate and weather into a single index called the Climate Index for Tourism (CIT). However, mainly because it relies on actual observations of atmospheric conditions and is designed for $3 \mathrm{~S}$ tourism rather than general tourism activities [42, 49], it is not suitable in the examination of climate resource for activities. Yu et al. [25] developed a Modified Climate Index for Tourism (MCIT) to measure climate as a tourism resource by combining two tourism-related climates elements, visibility and significant weather (e.g., rain, lightning, hail, and snow). However, MCIT does not make use of tourist climatic preferences from relevant literatures [26]. Based on the growing literature of tourists' stated climatic preferences, Scott et al. [26] proposed Holiday Climate Index, using part of the CIT model which overcomes all identified deficiencies and limitations of the Tourism Climate Index. For instance, variable rating scales and the component weighting system were both optimized and adjusted. Scott's HCI is employed in this analysis due to its comprehensive nature and universal applicability.

The tourist climate comfortable period (TCCP) is of great significance to the architectural design, the health of tourists, and the development of the tourism industry. In previous studies, the low temporal resolution of climate data (i.e., monthly data) as the time granularity has limited 
relevance of tourist decision-making [50, 51]. Compared with the daily scale, it is not conducive to comparison and analysis of interregional differences. The climate condition in different regions in China is rather heterogeneous. Therefore, it is essential to understand the temporal patterns of TCCP totality in China. However, very few researches have been conducted regarding evaluation of China's daily climate adaptation using the Tourism Climate Index for tourism purposes. Fang and Yin [41] focus on climate in tourism seasonality and assesses the impacts of climate resources on China's tourism seasonality using the Tourism Climate Index (TCI). On the basis of daily meteorological statistics from 1966 to 2015 in Guangxi, Zhu and Zhao [52] calculated TCI and analyzed tourism climate comfort characteristics on the resort Lu Mountain in China. However, studies that used TCI for China has not adequately represented tourism market in the light of changing climate.

For this purpose, in this study, HCI and climatic data of 775 synoptic stations of China were used to evaluate the climate comfort and climate change on tourism. Also, temporal and spatial distributions of tourism climate index using ArcGIS 10.2, such as Kriging interpolation, have been analyzed, and appropriate times of tourist presence in different cities have been determined. These findings provide important implications for future research in assessing current and future climatic suitability for tourism.

\section{Data Sources and Methods}

3.1. Data Sources. The meteorological observation data required in the analysis are the standard values of the surface climate dataset in China, which were obtained from the China National Meteorological Information Center (http:// data.cma.cn/). This dataset includes station attribute information (e.g., station ID, longitude, and latitude) and daily climatology data (e.g., temperature, humidity, precipitation, sunshine, and wind speed), which have been used extensively in climate-related research across China [15, 53]. Mainland China was selected as the study region for this paper because of its irreplaceable importance as a global tourism destination, in addition to the availability of higher temporal resolution geospatial data required for current climate analysis. Based on the availability and stability of the data, we selected 775 meteorological stations nationwide from 1981 to 2010. All of the data required by the HCI were obtained by using MATLAB. And, we used the Thiessen polygon division to carry out the area-weighted of the station data through ArcGIS 10.2 software (Figure 1). Taiwan province and some remote islands have been excluded from this study due to a lack of long-term monitoring data series in some parts of these regions.

\subsection{Methods}

3.2.1. Holiday Climate Index (HCI). The Holiday Climate Index (HCI) was developed by Scott et al. [26] as a composite measure to more accurately assess the climatic suitability of destinations for leisure tourism. The HCI integrates all three facets (thermal comfort (TC), aesthetic $(A)$, and physical $(P)$ )

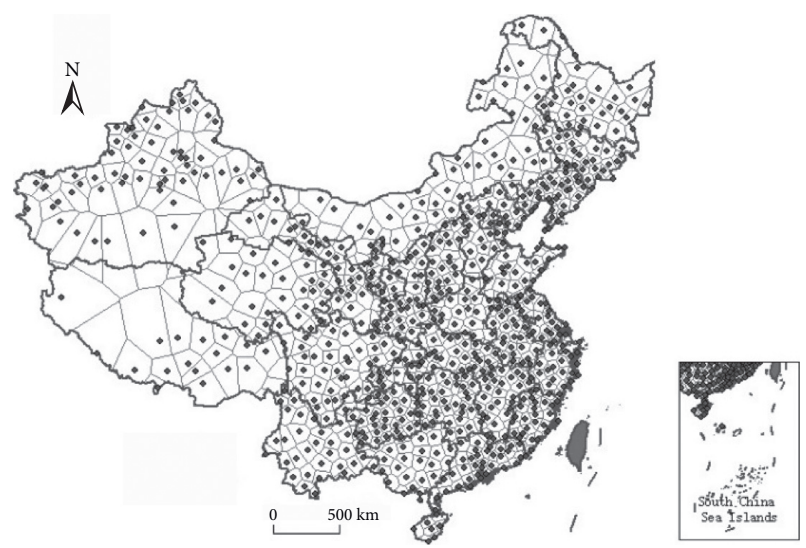

- Stations

FIGURE 1: Thiessen polygon division of the NRCS and NBMOS in mainland China (1981-2010).

of climate, which not only reflects the individual's response to weather but also reflects climate important to leisure tourism activities. It contains daily maximum air temperature and mean relative humidity (TC), cloud cover $(A)$, and precipitation and wind speed $(P)$. All of them were combined into three subindices, which are outlined in Table 1 .

The combined HCI formula takes on the following expression:

$\mathrm{HCI}=4(\mathrm{TC})+2(A)+(3($ precipitation $)+$ wind $)$,

where TC is the Thermal Comfort Index and $A$ is an Aesthetic Index. And, the thermal comfort component of the $\mathrm{HCI}$ uses effective temperature $\left(\mathrm{ET},{ }^{\circ} \mathrm{C}\right)$, which is a combination of air temperature and relative humidity. Each daily climate variable is rated on an optimal ranging from 0 to 10 (Table 2), with an overall HCI score of 0 (potentially dangerous for tourists) to 100 (ideal for tourism). In order to reflect off the HCI more directly, we proposed a simplified rating system combined with Mieczkowski's classification scheme method [23, 41]. (Table 3).

3.2.2. Linear Trend Analysis. The linear trend analysis is a common method used to analyze the tendency rate of climate change and trend patterns of the area [54-56]. And, in this paper, by matching observation stations and removing incomplete and invalid data, we choose a total number of 775 stations for about 30 years, which were found to be homogeneous without any missing date and were finally retained in the linear trend analysis to evaluate the changes in the TCCP from 1981 to 2010.

The linear trend analysis can be expressed as

$$
y_{i}=a+b t_{i}
$$

where $y_{i}$ represents the sliding mean TCCP of one meteorological station in the length of $i$ time in years, $t_{i}$ is the time series corresponding to $y_{i}$, bis the trend value, $b * 10$ (day/10 years) is usually adopted to carry out the corresponding analysis, and $a$ is the regression constant, which is obtained by the least squares method: 
Table 1: Subindices of Scott's Holiday Climate Index.

\begin{tabular}{lcc}
\hline Subindex & Daily climate variables & Weight $(\%)$ \\
\hline Thermal comfort $(\mathrm{TC})$ & Maximum daily temperature $\left({ }^{\circ} \mathrm{C}\right)$ & 40 \\
Aesthetic $(A)$ & Mean relative humidity $(\%)$ & 20 \\
Physical $(P)$ & Cloud cover $(\%)$ & 30 \\
& Precipitation $(\mathrm{mm})$ & 10 \\
\hline
\end{tabular}

TABLE 2: Rating scheme of each climate variable.

\begin{tabular}{lcccc}
\hline Rating & Effective temperature $\left({ }^{\circ} \mathrm{C}\right)$ & Daily precipitation $(\mathrm{mm})$ & Daily cloud cover $(\%)$ & Wind speed $(\mathrm{km} / \mathrm{h})$ \\
\hline 10 & $23-25$ & 0 & $11-20$ & $1-9$ \\
9 & $20-22,26$ & $<3$ & $1-10,21-30$ & $10-19$ \\
8 & $27-28$ & $3-5$ & $0,31-40$ & $0,20-29$ \\
7 & $18-19,29-30$ & & $41-50$ & $30-39$ \\
6 & $15-17,31-32$ & $6-8$ & $61-60$ & 40 \\
5 & $11-14,33-34$ & & $71-80$ & $40-49$ \\
4 & $7-10,35-36$ & & $81-90$ & \\
3 & $0-6$ & $9-12$ & $90-99$ & \\
2 & $-5-1$ and 37-39 & & 100 & $50-70$ \\
1 & $\leq-6$ & $>12$ & & $>70$ \\
0 & $\geq 39$ & $>25$ & & \\
-1 & & & & \\
\hline
\end{tabular}

TABle 3: HCI's rating scheme.

HCI categories of Scott [26] A simplified rating system for HCI

Ideal (90-100)

Excellent (80-89)

Very good (70-79)

Good (60-69)

Acceptable (50-59)

Marginal (30-49)

Unacceptable (10-29)

Dangerous (0-9)

$$
a=\frac{1}{n} \sum_{i=1}^{n} y_{j}-b \frac{1}{n} \sum_{i=1}^{n} t_{i}, b=\frac{\sum_{i=1}^{n} y_{i} t_{i}-(1 / n)\left(\sum_{i=1}^{n} y_{i}\right)\left(\sum_{i=1}^{n} t_{i}\right)}{\sum_{i=1}^{n} t_{i}^{2}-(1 / n)\left(\sum_{i=1}^{n} t_{i}\right)^{2}},
$$

where $t_{i}$ is the starting year and $n$ is the length of time in years. When $b$ is greater than $0, y_{i}$ increases over time. When $b$ is less than $0, y_{i}$ in the region decreases over time. The size of $b$ reflects the rising or declining of tendency rate of WPI change in the region.

\section{Results}

4.1. Spatial Pattern of TCCP in China. The area-weighted mean TCCP $(\mathrm{HCI} \geq 80)$ for the regions of mainland China was obtained by Thiessen polygon through ArcGIS 10.2 software. The TCCP lasts for 131.38 days, of which the summer (June-August) has the highest TCCP, with the TCCP reaching 53.83 days, accounting for $41 \%$ of the annual climate comfort period (Table 4). Results obtained in spring (March-May) are similar to those of autumn
TABLe 4: Annual average tourist climate comfortable period in mainland China (1981-2010).

\begin{tabular}{lccccc}
\hline TCCP (day) & Year & Spring & Summer & Autumn & Winter \\
\hline Area-weighted & 131.38 & 34.3 & 53.8 & 36.4 & 6.9 \\
\hline
\end{tabular}

(September-November), each accounting for more than $1 / 4$ of the annual comfort period. The comfort period in winter (December-February) is very short and lasts for 6.9 days. That is to say, only $1 / 3$ of the 366 days a year $(35.9 \%$ of the total number of days) is strictly "excellent," and the proportion of TCCP in spring and autumn is closer to the annual level (37.6\% and $40 \%$ respectively), which accounts for more than $1 / 3$ of the season. In the longest comfort period, the "excellent" days are more than $1 / 2$ days of the summer season $(58.5 \%)$, and in the winter, it is hardly to say "excellent" in mainland China.

Overall, most of the areas have an "excellent" climate for tourism, such that tourists may visit anytime with many choices available. The natural condition of different region in China is rather heterogeneous, for China has a vast territory. Accompanied by seasonal variations, regional variation of TCCP is more noticeable in mainland China. Based on ArcGIS 10.2 software, spatial interpolation was carried out by using the kriging interpolation method to obtain the spatial distribution of annual average TCCP (Figure 2) and quarterly average TCCP (Figure 3 ).

The number of "excellent" days $(\mathrm{HCI} \geq 80)$ during 1981-2010, as a picture of current tourism comfort levels throughout China, is presented in Figure 2. In terms of climate resources, China shows notable variation in the spatial pattern of the annual average TCCP, varying from 14 


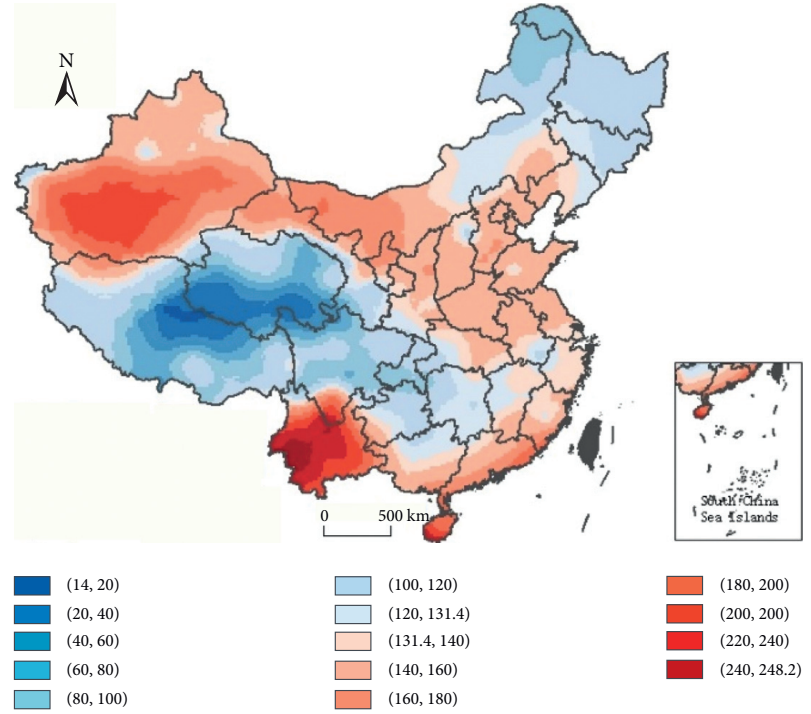

FIgUre 2: The spatial pattern of the annual average TCCP in China (1981-2010).

to 248.2. The regions with the lowest number of "excellent" days (less than the national average), include the Tibetan Plateau area (e.g., Tibet and Qinghai) and the most parts of northeast China (e.g., Heilongjiang Province and Jilin Province). Yunnan Province is the most attractive area with more than 200 days. Kunming, Yunnan province, enjoys fame as the "City of Eternal Spring." As is well known, owing to the special geographic location (low latitude plateau), the climate of Yunnan Province is neither too cold in winter nor too hot in summer. So, it seems like spring all year round.

As shown in Figure 3(a), during the spring season, the longest TCCP occurs in the south-central part of Yunnan Province, and the duration lasts for more than 60 days. The shortest TCCP appears in the mideast region of the QinghaiTibet plateau. From a wide view of TCCP in China, in addition to Yunnan province, the TCCP in high latitude and altitude areas is lower than the national average due to the greater influence of temperature. Although the temperature in the south China has warmed up in the spring, it is still cloudy and rainy and TCCP is slightly lower than that of the national average too (Figure 3(a)). During the spring and autumn, the TCCP of mainland China generally maintained a similar spatial pattern with the annual average. For the most part of eastern and southern China, autumn is less rainy, warm sunny, clear and crisp, and cloudless for the comfortable season, which can be generally attributed to the decreasing humidity (Figure 3(c)). In summer and winter, China obviously exhibits a latitudinal gradation of tourism climatic attractiveness. In summer, the "excellent" conditions mainly occur in north of Qinling Mountains-Huaihe River (Figure 3(b)). In winter, the regions considered as "excellent" are located in the south of the Five Ridges and Yunnan Province, and the regions considered as less "excellent" days are located in the northeast and northwest areas, and Inner Mongolia (Figure 3(d)). It indicates that the tourism climate comfort condition in winter is not optimistic. Whether a region has an attractive TCCP for tourists in summer and winter, in general, depends on the temperature, which is significantly influenced by the latitude.

There are plenty of natural tourism resources in Yunnan province, especially the climate resources have great competitive strengths in tourism market all over the world. Except for summer, Yunnan province has the most abundant tourism climate resources, and its value is far higher than the national average, which are very suitable for tourists to travel. The climatic condition is the prerequisite for developing tourism. However, no matter what season it is, the deficiency in TCCP hinders the development of the QinghaiTibet plateau region, especially the border areas of Tibet, Qinghai, and Sichuan provinces. It should be kept in mind that the results in our paper probably cannot reflect the actual tourism activities in each region, because we only consider the climatic conditions, and some other factors, such as institutional factors and cultural and historical factors (such as historical sites and scenic spots), have not been considered in the study. But, the climate on the border areas of Tibet, Qinghai, and Sichuan provinces has also played certain restriction roles in tourism development, such as climate-induced some extreme weather events. In order to promote the sustainable development of tourism activities such places, it is necessary to develop and optimize the season tourism products to alter the traditional tourism destination image and to improve the defensive capabilities for severe weather.

4.2. Temporal Evolution Analysis. China is one of the sensitive areas of global climate change, and its weather conditions improved during the past 30 years (Figure 4 ). Thus, it can be seen that the global climate change has a positive impact on the climate comfort period of tourism in China. Then, we calculated the linear trend analysis of 775 stations, and $75 \%$ of the meteorological stations passed the 0.05 level of significance (the number of stations: year 664, spring 638, summer 590, autumn 661, and winter 671). The spatial distribution of annual average TCCP (Figure 5) and quarterly average TCCP (Figure 6) during 1981-2010 is obtained.

The TCCP in most regions showed an increasing trend from 1981 to 2010. Only at the junction of the BeijingTianjin-Hebei region and most areas of Shandong Province, the TCCP decreased slightly (Figure 5). By calculating the 15-year difference (1996-2010 average minus 1981-1995 average) of Shandong Province, it is found that the mean annual precipitation has increased by $46.2 \mathrm{~mm}$ and the average annual sunshine duration has decreased by $0.47 \mathrm{~h}$. However, it will reduce the quality of overall tourists' experience and cause adverse effects. It means, at the local scale, this is likely influenced by the topography and environment compared with the regions at a similar latitude. The increasing rate is more obvious in the areas of the ShaanxiGansu-Ningxia region and parts of southeast China. Increasing and warmer temperatures will positively influence TCCP growth in the Shaanxi-Gansu-Ningxia region, which has great potential to improve the tourism and economic and environmental sustainability. 

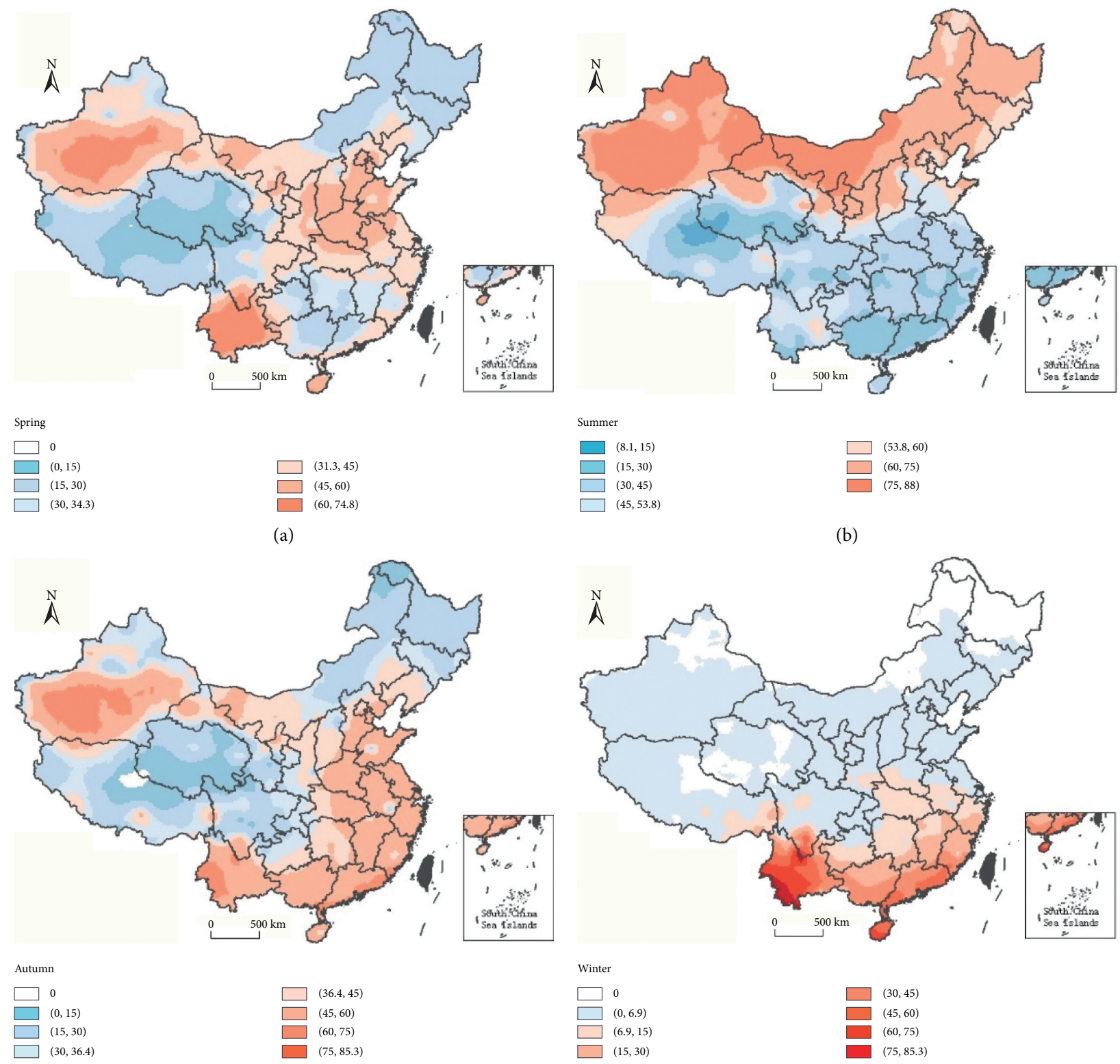

(a)

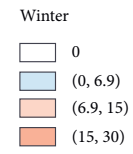

(c)

$\square(53.8,60)$

$\square(75,88)$

(b)

FIgURE 3: Spatial patterns of the seasonal average TCCP in China (1981-2010).

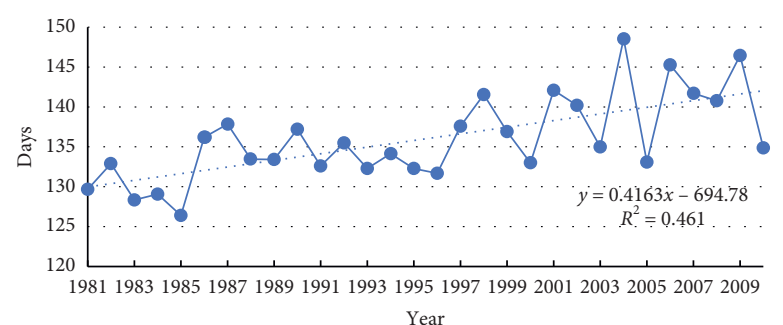

FIgURE 4: The annual average tourist climate comfortable period in mainland China (1981-2010). 


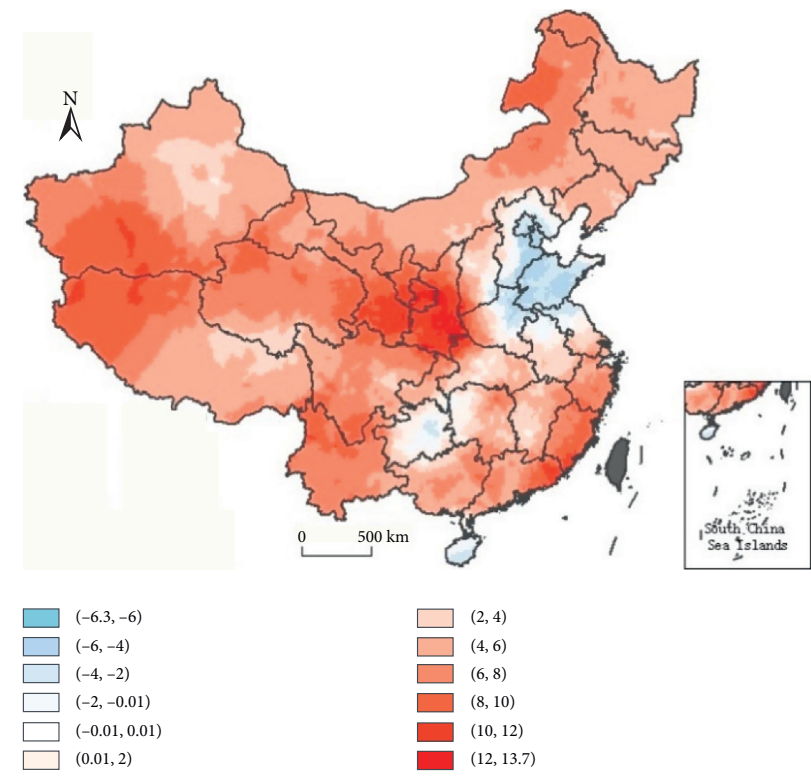

FIGURE 5: Spatial evolution of the annual average climate comfortable period in China (1981-2010).
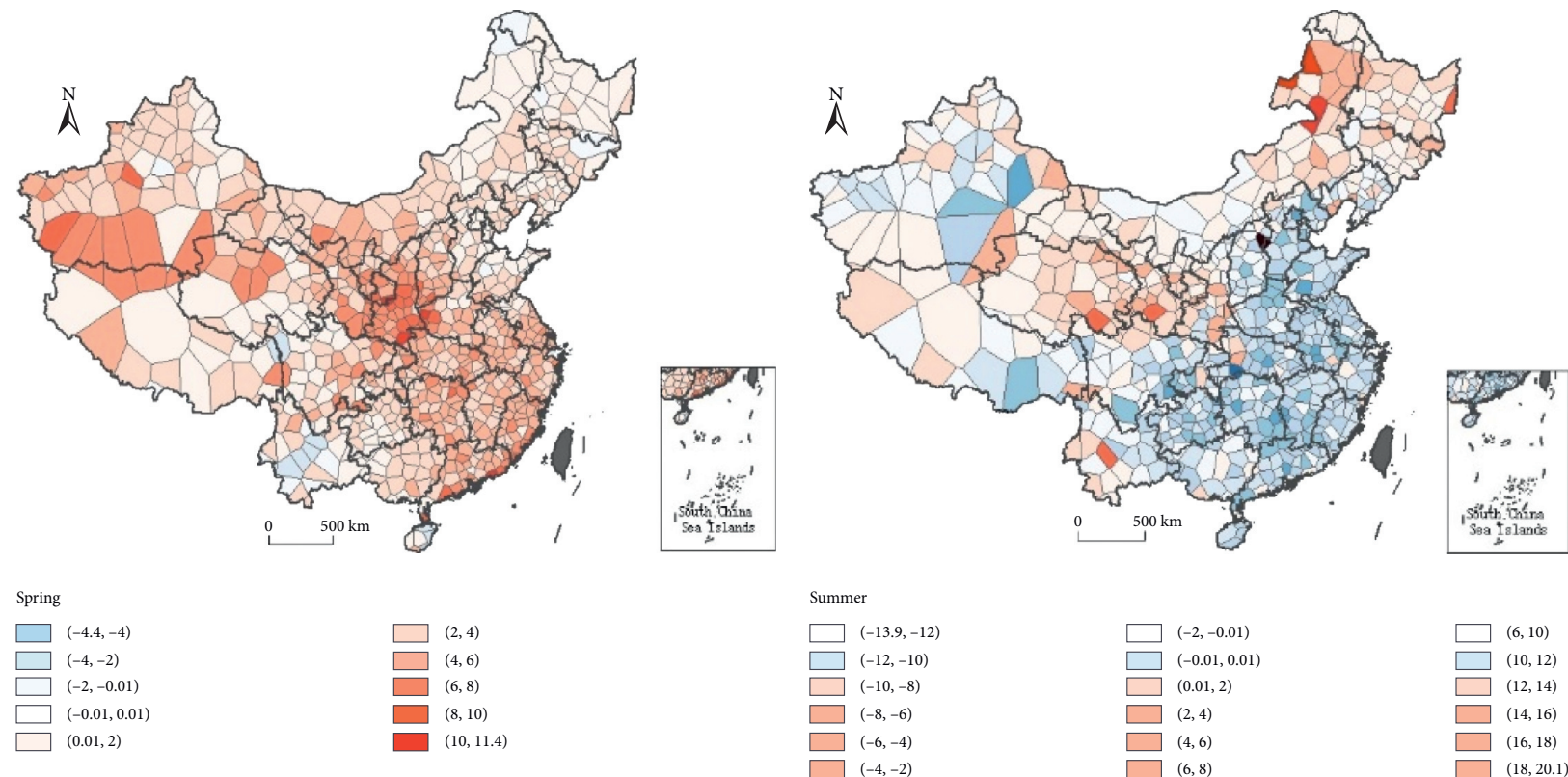

(a)

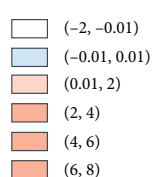

(b)

Figure 6: Continued. 

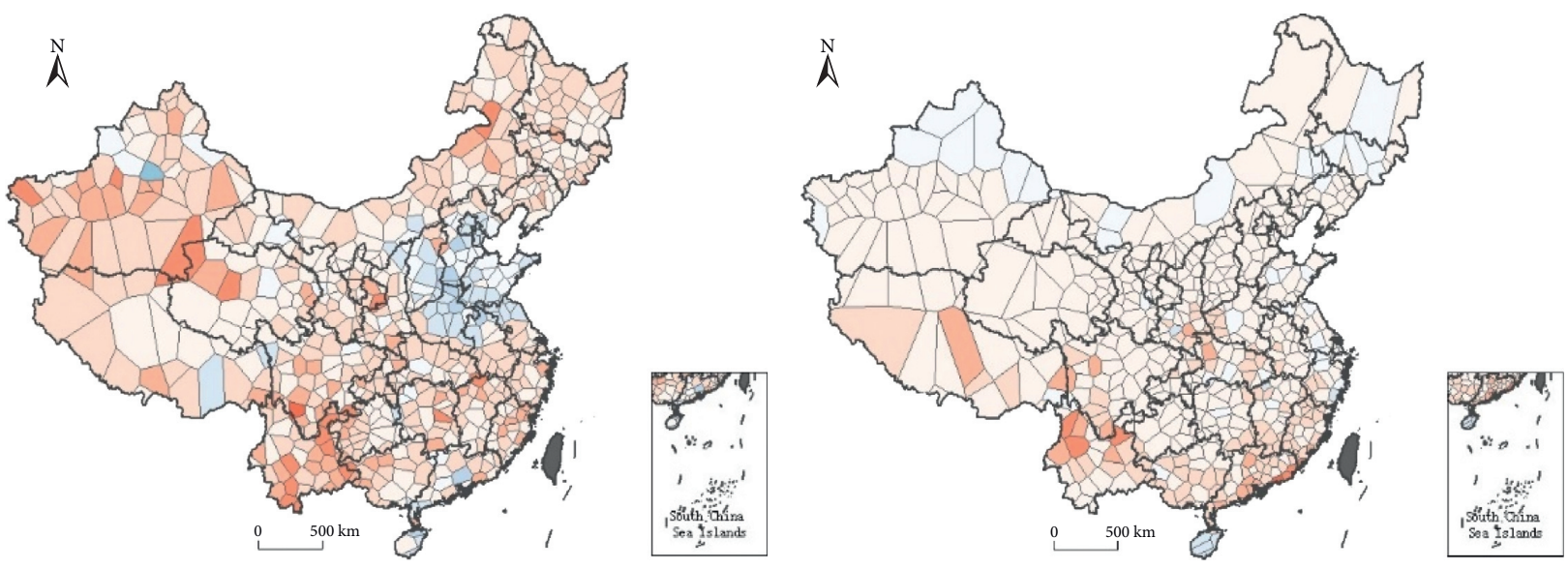

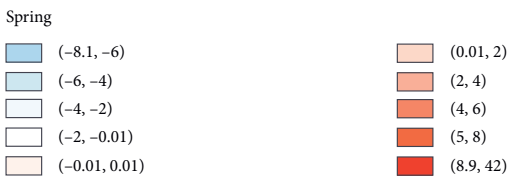

(c)

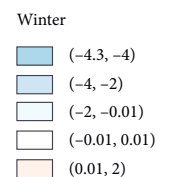

$(0.01,2)$

Figure 6: Spatial evolution of the seasonal average TCCP in mainland China (1981-2010).

China's weather conditions improved from 1981 to 2010. Specifically, $95.2 \%$ of the area of China is projected to experience increasing weather conditions. With the development of social economy, the areas with an obvious increase in TCCP can adjust some forward thinking and adaptation polices to redistribution of climate resources for tourism. This urges the tourism to adjust the strategic thinking, core, and impetus of development put in on the increasing of climate resources, and summer/winter tourism goes along with this trend. China implements active measures to address climate change in the future and focuses on the mitigation of and adaptation to climate change in regions with reduced TCCP conditions.

The number of meteorological stations shows the station densities transit from the high-density region to the low-density region on the whole, while in southeast China, there are relatively dense areas, and in northwest China and Qinghai-Tibet region, there are relatively sparse areas. Create Thiessen Polygons to divide the area covered by the meteorological station features into Thiessen or proximal zones, which can be used to display the regional spatial and seasonal variation. TCCP in most parts of China is increased, regardless of the seasons. And, the percentage of total areas with an increasing tendency in spring, autumn, and winter is $97.3 \%, 92.8 \%$, and $85.3 \%$. Prominent among them is spring (Figure 6(a)) and autumn (Figure 6(c)). Same like the spatial evolution of the annual TCCP in China (Figure 5), a negative TCCP growth rate occurs at the junction of Beijing-Tianjin-Hebei region and most areas of Shandong Province. The rate of TCCP area also tends to be reduced in the winter and mainly concentrated in the parts of Heilongjiang, Xinjiang, and eastern coastal areas (Figure 6(d)). Seasonal differences were most pronounced between summer and the other three seasons. Specifically, the proportion of the area with a linear trend rate of "positive" in summer, which covers 6.21 million $\mathrm{km}^{2}$ (64.5\% of the total area of China), is projected to experience improving weather conditions, and the increase of TCCP is shown in parts of northwest and northeast areas and Inner Mongolia (Figure 6(b)).

\section{Conclusion and Discussion}

5.1. Conclusion. The Holiday Climate Index (HCI) is a widely used indicator to assess the climate comfortable period on tourism. This paper presents an empirical analysis of the climate impact on tourism in China during the period of 1981-2010, by combining high-quality national meteorological datasets with ArcGIS. We used the HCI index to quantify the TCCP and explored the annual and seasonal TCCP and its spatial patterns in China and thus analyzed the time evolution characteristics of TCCP over the past 30 years.

The distribution of TCCP has significant seasonal and regional differences among different districts. In this study, TCCP $(\mathrm{HCI} \geq 80)$ is taken as the criterion to judge the tourism climate environment as the grade of "excellent". Moreover, according to the standard, the average annual TCCP in China is 131.4 days, of which the longest (53.8 days) is in summer, followed by autumn and spring ( 36.4 and 34.3 days), and the shortest in winter (6.9 days). Also, our results showed that the climates of most regions in China are comfortable for tourists during spring and autumn. In summer and winter, the spatial distribution of TCCP shows a latitudinal gradation. The most attractive area, with high levels of tourism comfort, is Yunnan, whereas the Tibetan Plateau area has the least attractiveness. From the perspective of the countrywide scale, another finding is that the tourism climate comfort period in most regions showed an increasing trend. However, the trend in the local regions in China, such as the junction of the Beijing-Tianjin-Hebei region and most areas of Shandong Province, decreased 
from 1981 to 2010 . The importance of TCCP for tourism, as well as the spatial distribution of tourism seasonality affected by changing climate, are underlined by analytical results.

In addition, in summer and winter, China obviously exhibits a latitudinal gradation of tourism climatic attractiveness. Due to cool and comfortable in summer, the “excellent" days mainly occur in most areas north of Qinling Mountains-Huaihe River (Figure 3(b)). In winter, the regions considered as "excellent" are located in the south of the southern coastal area and Yunnan Province, and the regions considered as less "excellent" days are located in the northeast and northwest areas and Inner Mongolia (Figure 3(d)). Whether a region has an attractive TCCP for tourists in summer and winter, in general, depends on the temperature, which is significantly influenced by the latitude.

5.2. Discussion. Tourism climate is a key factor for policymakers and visitors. Our results can be used as a reference for travelling, planning of destinations, adaptions for reducing seasonality, etc. That will be very clear on the HCI map if tourists decided to choose more comfortable regions to travel to and visit.

Climate change is causing several changes in temperature which in turn greatly changes the lifestyle of people. Against this background, summer tourism and winter tourism are gradually emerging. The results reveal that the tourism climate in summer is significantly related to the latitude and elevation across China. There is a desire to avoid hot weather in China, especially in the southeast, where people's consumption ability is high. Most parts of northern China are comfortable for summer tourism from the perspective of tourism climate. Thus, they could provide a pleasant climate for tourists wanting to avoid summer heat from southern China. The comfortable and warm climate in winter is the most basic condition for winter tourism. In winter, the TCCP goes up as the latitude reduces. This shows that the south has a more comfortable climate. Compared with summer tourism, the climate resources of winter tourism are relatively scarce, mainly concentrated in Yunnan, Hainan, and Guangzhou provinces. In southern China, winter resorts could be developed to attract tourists from northern China, especially for the hot Chinese Spring Festival Holiday leisure. A favorable climate should be integrated with other tourism resources in the design of tourism products.

In addition, we also proposed that northwest of China, as one of the regions with higher TCCP (especially in spring, summer and autumn), is the key in the way of shifting the favorable climate resource advantages into the economic ones. Environmental resources have become an integral part of modern destination development and competitiveness models. Tourism has the potential to lift the northwest people out of poverty through the employment and entrepreneurial opportunities it provides.

In this way, based on the Holiday Climate Index, it is meaningful for summer and winter tourism to evaluate the competitiveness and suitability of summer and winter tourism and helpful to cultivate a strong competitive summer and winter tourism destination and product system. Additionally, it also can provide some scientific understandings for human settlements' environmental constructions and be helpful in improving local or regional resilience responding to global climate change.

Based on this basic understanding of the TCCP, the following study can further explore its possible influence on population distribution, industrial expansion, and tourism development, which will enrich the correlation studies of the TCCP. To further improve the accuracy of this study, in the Kriging interpolation method analysis, we should consider the topographic factors. In addition, in order to enrich the tourism climate's practical application fields for future adaptation, additional research is required to combine the results with "comfortable period" and "uncomfortable period" to assess the spatiotemporal distribution of climate resources for tourism seasonality responding to the projected global warming, managing the risks posed in tourism by the impacts of climate change, as well as to deal with these changes flexibly.

\section{Data Availability}

The meteorological observation data used to support the findings of this study were supplied by the China National Meteorological Information Center under license. Requests for access to these data should be made to (http://data.cma. $\mathrm{cn} /)$.

\section{Conflicts of Interest}

The authors declare that they have no conflicts of interest.

\section{Acknowledgments}

This work was supported by the National Natural Science Foundation of China (grant no. 41675147) and the China Scholarship Council (CSC no. 201906140192). The authors would also like to thank Dr. Ning (Chris) Chen of the University of Canterbury for providing linguistic assistance during the preparation and revision of this manuscript.

\section{References}

[1] D. Scott, C. Lemieux, and L. Malone, "Climate services to support sustainable tourism and adaptation to climate change," Climate Research, vol. 47, no. 1, pp. 111-122, 2011.

[2] D. R. Perkins and K. G. Debbage, "Weather and tourism: thermal comfort and zoological park visitor attendance," Atmosphere, vol. 7, no. 3, pp. 1-17, 2016.

[3] S. S. Abed and A. Matzarakis, "Quantification of the tourism climate of Algeria based on the climate-tourism-informationscheme," Atmosphere, vol. 9, no. 7, p. 250, 2018.

[4] S. Becken, "A review of tourism and climate change as an evolving knowledge domain," Tourism Management Perspectives, vol. 6, pp. 53-62, 2013.

[5] Y. Fang, J. Yin, and B. Wu, "Climate change and tourism: a scientometric analysis using CiteSpace," Journal of Sustainable Tourism, vol. 26, no. 1, pp. 108-126, 2017. 
[6] D. Scott, C. M. Hall, and S. Gössling, "Global tourism vulnerability to climate change," Annals of Tourism Research, vol. 77, pp. 49-61, 2019.

[7] M. Beccali, V. Strazzeri, M. L. Germanà, V. Melluso, and A. Galatioto, "Vernacular and bioclimatic architecture and indoor thermal comfort implications in hot-humid climates: an overview," Renewable and Sustainable Energy Reviews, vol. 82, pp. 1726-1736, 2018.

[8] M. L. Costa, M. R. Freire, and A. Kiperstok, "Strategies for thermal comfort in university buildings-the case of the faculty of architecture at the Federal University of Bahia, Brazil," Journal of Environmental Management, vol. 239, pp. 114-123, 2019.

[9] G. R. McGregor and J. K. Vanos, "Heat: a primer for public health researchers," Public Health, vol. 161, pp. 138-146, 2018.

[10] J. K. Vanos, E. Kosaka, A. Iida et al., "Planning for spectator thermal comfort and health in the face of extreme heat: the Tokyo 2020 Olympic marathons," Science of The Total Environment, vol. 657, pp. 904-917, 2019.

[11] C. K. C. Lam, M. Loughnan, and N. Tapper, "Visitors' perception of thermal comfort during extreme heat events at the Royal Botanic Garden Melbourne," International Journal of Biometeorology, vol. 62, no. 1, pp. 97-112, 2018.

[12] L. Matthews, D. Scott, and J. Andrey, "Development of a datadriven weather index for beach parks tourism," International Journal of Biometeorology, pp. 1-14, 2019.

[13] C. R. de Freitas, D. Scott, and G. McBoyle, "A second generation climate indsex for tourism (CIT): specification and verification," International Journal of Biometeorology, vol. 52, no. 5, pp. 399-407, 2008.

[14] C. R. de Freitas and E. A. Grigorieva, "A comprehensive catalogue and classification of human thermal climate indices," International Journal of Biometeorology, vol. 59, no. 1, pp. 109-120, 2015.

[15] M. S. Sun and S. Li, "Empirical indices evaluating climate comfortableness: review and prospect," Tourism Tribune, vol. 30, no. 12, pp. 19-34, 2015.

[16] C. R. de Freitas and E. A. Grigorieva, "A comparison and appraisal of a comprehensive range of human thermal climate indices," International Journal of Biometeorology, vol. 61, no. 3, pp. 487-512, 2017.

[17] R. Brake and G. Bates, "A valid method for comparing rational and empirical heat stress indices," The Annals of Occupational Hygiene, vol. 46, no. 2, pp. 165-174, 2002.

[18] K. Blazejczyk, Y. Epstein, G. Jendritzky, H. Staiger, and B. Tinz, "Comparison of UTCI to selected thermal indices," International Journal of Biometeorology, vol. 56, no. 3, pp. 515-535, 2012.

[19] Y. C. Yan, S. P. Yue, X. H. Liu, D. D. Wang, and H. Chen, "Advances in assessment of bioclimatic comfort conditions at home and abroad," Advances in Earth Science, vol. 28, no. 10, pp. 1119-1125, 2013.

[20] Z. K. Yu, G. N. Sun, Z. W. Luo, and Q. Feng, "An analysis of climate comfort degree and tourism potential power of cities in Northern China in summer to the north of $40^{\circ} \mathrm{N}$," Journal of Natural Resources, vol. 30, no. 2, pp. 327-339, 2015.

[21] X. Chi, R. Li, U. Cubasch, and W. Cao, "The thermal comfort and its changes in the 31 provincial capital cities of mainland China in the past 30 years," Theoretical \& Applied Climatology, vol. 132, no. 1-2, pp. 599-619, 2018.

[22] J. Yang, Z. Zhang, X. Li, J. Xi, and Z. Feng, "Spatial differentiation of China's summer tourist destinations based on climatic suitability using the universal thermal climate index,"
Theoretical and Applied Climatology, vol. 134, no. 3-4, pp. 859-874, 2018.

[23] Z. Mieczkowski, "The tourism climatic index: a method of evaluating world climates for tourism," The Canadian Geographer/Le Géographe Canadien, vol. 29, no. 3, pp. 220-233, 1985.

[24] R. Morgan, E. Gatell, R. Junyent, A. Micallef, E. Özhan, and A. T. Williams, "An improved user-based beach climate index," Journal of Coastal Conservation, vol. 6, no. 1, pp. 41-50, 2000.

[25] G. Yu, Z. Schwartz, and J. E. Walsh, "A weather-resolving index for assessing the impact of climate change on tourism related climate resources," Climatic Change, vol. 95, no. 3-4, pp. 551-573, 2009.

[26] D. Scott, M. Rutty, B. Amelung, and M. Tang, "An intercomparison of the holiday climate index (HCI) and the tourism climate index (TCI) in Europe," Atmosphere, vol. 7, no. 6, 2016.

[27] G. Mahtabi and F. Taran, "Comparing the effect of climate condition on tourism calendar in arid and humid cities using holiday climate index (HCI) (case study: Isfahan and Rasht)," Desert, vol. 23, no. 1, pp. 63-73, 2018.

[28] Z. Hejazizadeh, A. Karbalaee, S. A. Hosseini, and S. A. Tabatabaei, "Comparison of the holiday climate index (HCI) and the tourism climate index (TCI) in desert regions and Makran coasts of Iran," Arabian Journal of Geosciences, vol. 12, 2019.

[29] A. Öztürk and R. GÖRAL, "Climatic suitability in destination marketing and holiday climate index," An Online International Research Journal, vol. 4, no. 1, pp. 619-629, 2018.

[30] M. Rutty, D. Scott, L. Matthews et al., "An inter-comparison of the holiday climate index (HCI: beach) and the tourism climate index (TCI) to explain Canadian tourism arrivals to the caribbean," Atmosphere, vol. 11, no. 4, p. 412, 2020.

[31] F. C. Houghton and C. P. Yaglo, "Determining equal comfort lines," Journal of the American Society of Heating and Ventilating Engineers, vol. 29, pp. 165-176, 1923.

[32] E. C. Thom, A New Concept for Cooling Degree Days, Weather Bureau, Silver Spring, MA, USA, 1957.

[33] W. H. Terjung, "Physiologic climates of the conterminous United States: a bioclimatic classification based on man," Annals of the Association of American Geographers, vol. 56, no. 1, pp. 141-179, 1966.

[34] P. O. Fanger, Thermal Comfort: Analysis and Applications in Environmental Engineering, Danish Technical Press, Copenhagen, Denmark, 1970.

[35] P. Höppe, "The physiological equivalent temperature-a universal index for the biometeorological assessment of the thermal environment," International Journal of Biometeorology, vol. 43, no. 2, pp. 71-75, 1999.

[36] G. Jendritzky, R. de Dear, and G. Havenith, "UTCI-Why another thermal index?" International Journal of Biometeorology, vol. 56, no. 3, pp. 421-428, 2012.

[37] S. Gössling, M. Bredberg, A. Randow, E. Sandström, and P. Svensson, "Tourist perceptions of climate change: a study of international tourists in Zanzibar," Current Issues in Tourism, vol. 9, no. 4-5, pp. 419-435, 2006.

[38] M. Rutty and D. Scott, "Comparison of climate preferences for domestic and international beach holidays: a case study of Canadian travelers," Atmosphere, vol. 7, no. 2, 2016.

[39] S. Becken, "The importance of climate and weather for tourism," Land Environment and People (LEaP) Background Paper, pp. 4-13, Lincoln University, Lincoln, New Zealand, 2010. 
[40] G. Dubois, J. P. Ceron, C. Dubois, M. D. Frias, and S. Herrera, "Reliability and usability of tourism climate indices," Earth Perspectives, vol. 3, no. 1, 2016.

[41] Y. Fang and J. Yin, "National assessment of climate resources for tourism seasonality in China using the tourism climate index," Atmosphere, vol. 6, no. 2, pp. 183-194, 2015.

[42] H. Li, C. Goh, K. Hung, and J. L. Chen, "Relative climate index and its effect on seasonal tourism demand," Journal of Travel Research, vol. 57, no. 2, pp. 178-192, 2018.

[43] J. Huang, L. Li, C. Tan, J. Sun, and G. Wang, "Mapping summer tourism climate resources in China," Theoretical and Applied Climatology, vol. 137, no. 3-4, pp. 2289-2302, 2019.

[44] D. Scott and G. McBoyle, "Using a "tourism climate index" to examine the implications of climate change for climate as a tourism resource," in Proceedings of the First International Workshop on Climate, Tourism and Recreation, pp. 69-88, Halkidiki, Greece, 2001.

[45] S. L. Perch-Nielsen, B. Amelung, and R. Knutti, "Future climate resources for tourism in Europe based on the daily tourism climatic index," Climatic Change, vol. 103, no. 3-4, pp. 363-381, 2010.

[46] B. Bakhtiari, A. Bakhtiari, and Z. Afzali, "Gorouh Investigation of climate change impacts on tourism climate comfort in Iran," Global NEST Journal, vol. 20, no. 2, pp. 291-303, 2018.

[47] D. Mahmoud, G. Gamal, G. Gamal, and T. Abou El Seoud, "The potential impact of climate change on Hurghada city, Egypt, using tourism climate index," GeoJournal of Tourism and Geosites, vol. 25, no. 2, pp. 496-508, 2019.

[48] M. Tang, "Comparing the "tourism climate index" and "holiday climate index" in major European urban destinations," Master's thesis, University of Waterloo, Waterloo, Canada, 2013.

[49] Q.-p. Cheng and F.-l. Zhong, "Evaluation of tourism climate comfort in the Grand Shangri-La region," Journal of Mountain Science, vol. 16, no. 6, pp. 1452-1469, 2019.

[50] L. I. Qiu and G. Zhong, "Evaluation on climate resource for tourism in the region around Bohai," Journal of Arid Land Resources \& Environment, vol. 19, no. 2, pp. 149-153, 2005.

[51] L. Y. Peng, J. P. Cao, Y. F. Zhang, Q. L. Wang, and X. Q. Cheng, "The Western Sichuan plateau tourism and comfortable Zoige tourism climate resource analysis," Journal of Chengdu University of Information Technology, vol. 1, pp. 100-106, 2014.

[52] B. T. Zhu and H. R. Zhao, "Analysis and evaluation of tourism climate comfortableness in Guangxi during 1966-2015," Journal of Green Science and Technology, vol. 22, pp. 89-94, 2017.

[53] D. D. Yu and S. Li, "Scale of human thermal sensation using seasonal anchor method: a Chinese case study," Journal of Natural Resources, vol. 34, no. 8, pp. 1633-1653, 2019.

[54] S. Li, M. S. Sun, and W. J. Zhang, "Spatial patterns and evolving characteristics of climate comfortable period in the mainland of China: 1961-2010," Geographical Research, vol. 35, pp. 2053-2070, 2016.

[55] F. Y. Wei, Modern Climatic Statistical Diagnosis and Prediction Technology (II), China Meteorological Press, Beijing, China, 2007.

[56] S. Wang, H. Tian, W. S. Xie, W. Tang, and X. Dian, "A study on variations and comprehensive zoning of climate comfort degree in Anhui province in the past 50 years," Progress in Geography, vol. 31, no. 1, pp. 40-45, 2012. 